\title{
Effect of specific exercises on the sagittal profile of scoliotic spines
} M Rigo*, G Quera-Salvá, M Villagrasa, M Ferrer and A Casas

\author{
Address: E. Salvá Spinal Deformities rehabilitation Institute. Vía Augusta 185, 08021 Barcelona, Spain \\ Email: M Rigo* - lolo_rigo@hotmail.com \\ * Corresponding author
}

from 4th International Conference on Conservative Management of Spinal Deformities Boston, MA, USA. 13-16 May 2007

Published: 12 October 2007

Scoliosis 2007, 2(Suppl I):S7 doi:I0.1I86/I748-7|6I-2-SI-S7

This abstract is available from: http://www.scoliosisjournal.com/content/2/SI/S7

(c) 2007 Rigo et al; licensee BioMed Central Ltd.

\section{Objective}

To evaluate the three-dimensional (3D) correction effect, particularly in the sagittal plane, of Schroth exercises $[1,2]$ in patients with idiopathic scoliosis (IS) by using a surface topography system.

\section{Study design}

A retrospective unselected series of fifty consecutive patients (48 females, age 15.7 years) diagnosed with IS, were measured with the formetric system [3] before and after an intensive course of rehabilitation. This system provides quantitative values to asses the spine in the frontal, sagittal and transversal planes. We have designed a specific scale based on objective data in order to define the vertebral column in the sagittal plane as harmonic (minimum score 0) or disharmonic (maximum score 20).

\section{Results}

During the course of treatment, trunk imbalance improved from 11.6 to $8.1 \mathrm{~mm}(\mathrm{p}<0.001)$, and lateral deviation in the frontal plane decreased from 14.1 to 11.3 $\mathrm{mm}(\mathrm{p}<0.005)$. Surface rotation also decreased, from 7.4 degrees to 6.6 degrees $(\mathrm{p}<0.01)$. Although maximum and regional sagittal angles decreased, the harmonic score improved from 10.4 to 9.6 ( $\mathrm{p}<0.05)$.

\section{Conclusion}

Scoliotic patients tend to keep their sagittal regional angles close to normal values but showing a disharmonic configuration. Schroth exercises can correct the spine in $3 \mathrm{D}$, reducing such a disharmony.

\section{References}

I. Weiss HR: The effect of an exercise programme on VC and rib mobility in patients with IS. Spine 1991, 16:88-93.

2. Weiss HR, Lohschmidt K, El-Obeidi N, Verres Ch: Preliminary results and worse-case analysis of in patient scoliosis rehabilitation. Pediatric Rehabilitation 1997, I:35-40.

3. Asamoah V, Mellerowicz H, Venus J, Klöckner C: Measuring the surface of the back. Value in diagnosis of spinal diseases. Orthopade 2000, 29:480-489. 